\title{
Challenges for better care based on the course of maternal body mass index, weight gain and multiple outcome in twin pregnancies: a population-based retrospective cohort study in Hessen/Germany within 15 years
}

\author{
Julia Schubert ${ }^{1,2,4} \cdot$ Nina Timmesfeld ${ }^{5} \cdot$ Kathrin Noever $^{1,2} \cdot$ Birgit Arabin $^{1,2,3}$
}

Received: 1 October 2019 / Accepted: 13 January 2020 / Published online: 29 January 2020

(c) The Author(s) 2020

\begin{abstract}
Introduction Studies on maternal weight, gestational weight gain and associated outcomes in twin pregnancies are scarce. Therefore, we analyzed these items in a large cohort.

Methods Data from 10,603/13,725 total twin pregnancies from the perinatal database in Hessen, Germany between 2000 and 2015 were used after exclusion of incomplete or non-plausible data sets. The course of maternal and perinatal outcomes was evaluated by linear and logistic regression models.

Results The rate of twin pregnancies increased from 1.5 to $1.9 \%(p<0.00001)$. Mean maternal age and pre-pregnancy weight rose from 31.4 to 32.9 years and from 68.2 to $71.2 \mathrm{~kg}$, respectively $(p<0.001)$. The rates of women with a body mass index $\geq 30 \mathrm{~kg} / \mathrm{m}^{2}$ increased from 11.9 to $16.9 \%$ with a mean of $24.4-25.4 \mathrm{~kg} / \mathrm{m}^{2}(p<0.001)$. The overall increase of maternal weight/week was $568 \mathrm{~g}$, the 25 th quartile was 419 , the 75 th quartile $692 \mathrm{~g} /$ week. The total and secondary caesareans increased from 68.6 to $73.3 \%$ and from 20.6 to $39.8 \%$, respectively $(p<0.001)$. Rates of birthweight $<1500 \mathrm{~g}$ and of preterm birth $<28$ and from 28 to $33+6$ weeks all increased $(p<0.01)$. No significant changes were observed in the rates of stillbirth, perinatal mortality and NICU admissions.

Conclusion The global trend of the obesity epidemic is equally observed in German twin pregnancies. The increase of mean maternal weight and the calculated quartiles specific for twin pregnancies help to identify inadequate weight gain in twin gestations. Policy makers should be aware of future health risks specified for singleton and twin gestations.
\end{abstract}

Keywords Obesity $\cdot$ Gestational weight gain $\cdot$ Twin pregnancy $\cdot$ Preterm delivery $\cdot$ Caesarean delivery

\section{Introduction}

Julia Schubert

julia.a.schubert@gmail.com

1 Clara Angela Foundation, Alfred-Herrhausen-Straße 44, 58455 Witten, Germany

2 Clara Angela Foundation, Koenigsallee 36, 14193 Berlin, Germany

3 Department of Obstetrics Charite Humboldt University Berlin, Berlin, Germany

4 Center for Mother and Child, Philipps University Marburg, Baldingerstraße, 35033 Marburg, Germany

5 Department for Medical Computer Science, Biometry and Epidemiology, Ruhr-University Bochum, 44780 Bochum, Germany
The globally observed obesity epidemic also affects women at childbearing age [1] with either singleton or twin pregnancies. Maternal overweight and obesity have been shown to increase adverse maternal and neonatal short-term outcomes such as gestational diabetes (GDM) and hypertension in pregnancy (HDP), preeclampsia, protracted labor, caesarean delivery as well as congenital malformations, stillbirth, large and small for gestational age fetuses (LGA/SGA), shoulder dystocia and neonatal hypoglycaemia [2, 3]. Even more worrisome are the consequences for long-term health such as persistent maternal obesity, earlier rates of maternal metabolic and cardiovascular diseases and for the children - up to adulthood-earlier rates of metabolic syndrome and even earlier death rates [4]. However, most of the data derive from 
singleton pregnancies. For twin pregnancies, rates and risk factors of maternal body mass index (BMI) and gestational weight gain (GWG) are scarce.

A systematic review from 2014 concluded that GWG in twin pregnancies is "a neglected area of research" [5]. When the Institute of Medicine (IOM, now "National Academy of Medicine") established guidelines for weight gain during pregnancies in 2009, the recommendations for twin pregnancies were only provisional and did not include references for underweight women or for weekly weight gain [6]. Only a few publications reported on excessive gestational weight gain (EGWG) in twin gestation defined by provisional definitions $[7,8]$. EGWG was then associated with higher rates of HDP and preeclampsia, but lower rates for low birthweight $(\mathrm{BW})$.

In 2003, the twinning rates varied between $9.86 / 1000$ in Japan [9] up to 30.1/1000 in the United States (US) [10, 11], but all countries still report on increasing twinning rates [9-12]. Therefore, the purpose of this study was to describe the twinning rates within one representative federal state (Hessen) in Germany. More importantly, we have strived to illustrate changes of maternal BMI, GWG in absolute grams/ week and quartiles as well as available associated outcomes during 15 years within this large German Perinatal cohort between 2000 and 2015 .

\section{Materials and methods}

This study was based on data from the perinatal registry of hospital deliveries in Hessen, Germany, a federal state with $6,176,172$ inhabitants in 2015 [13]. Access for this research project was kindly provided by the office for quality management in Hessen, Germany, for the years 2000 up to 2015. The raw data were anonymously offered with respect to patients and centers, but extensive plausibility controls had still to be performed to exclude cases where relevant data were missing or not plausible. Data from twin pregnancies were only included when maternal weight was given, maternal height was $\geq 120 \mathrm{~cm}$ and an early ultrasound examination had confirmed the gestational age, all before 14 gestational weeks. Deliveries $<24$ gestational weeks, unknown maternal age or twins with unknown sex were excluded.

Examined maternal outcomes were: age, GWG in g/week and grouped as quartiles, BMI, HDP, caesarean delivery (total, secondary, emergency and only in the second twin) and postpartum haemorrhage ( $\mathrm{PPH}$, defined as a blood loss $>1000 \mathrm{ml}$ ).

The BMI was calculated as $\mathrm{kg} / \mathrm{m}^{2}$ and classified according to the WHO criteria: BMI $<18.5 \mathrm{~kg} / \mathrm{m}^{2}$ : "underweight"; BMI 18.5-24.9 kg/m²: "normal weight"; BMI $25.0-29.9 \mathrm{~kg} /$ $\mathrm{m}^{2}$ : "overweight"; BMI $\geq 30 \mathrm{~kg} / \mathrm{m}^{2}$ : "obesity" [14]. The difference between the maternal weight at the first examination and before delivery was divided by the duration of the interval in weeks to calculate the mean maternal GWG/week and associated quartiles, whereby the quartiles above $25 \%$ and below $75 \%$ were defined as "normal".

The incidence of HDP was indirectly calculated from clinical findings according to the definition by the International Society for the Study of Hypertension in Pregnancy (ISSHP) [15].

Gestational age at birth, BW, stillbirth, perinatal mortality (death at birth or within 7 days), neonatal intensive care unit (NICU) admissions, an APGAR score value below 7 after 5 min, a pH of the umbilical artery below 7.1 and a combination of the APGAR score and the $\mathrm{pH}$ of the umbilical artery were examined as neonatal outcomes.

The BW was categorized into five groups: below 1500 grams (g), 1500-1999 g, 2000-2499 g, 2500-2999 g and $\geq 3000 \mathrm{~g}$. Similarly, the gestational age at birth was categorized into three groups of preterm birth: $<28,28+0$ to $33+6$ and $34+0$ to $36+6$ gestational weeks.

Significant differences during the observation period were analyzed using a linear regression model for numeric outcomes or a logistic regression model for categorical outcomes. The programs for statistical evaluation were $\mathrm{R}$ for Windows 3.5.1, R Studio (Version 1.1.456) and Excel 2013. In all figures with relative results, the absolute numbers for each specific items were added.

\section{Results}

Between 2000 and 2015, 13,725 twin pregnancies of a total of 805,536 deliveries including all singleton, twin and multiple pregnancies were registered. This resulted in a mean twinning rate of $1.7 \%$ rising from $1.5 \%$ in 2000 to $1.9 \%$ in 2015, as shown in Fig. $1(p<0.00001)$. After the application

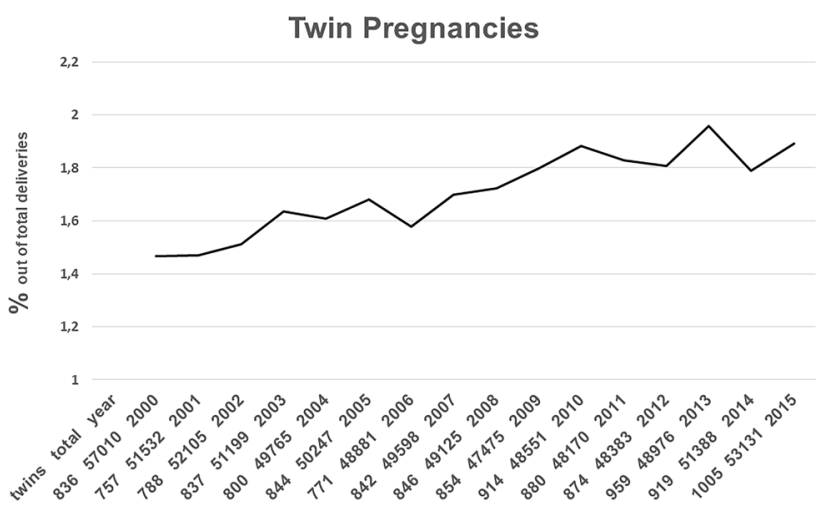

Fig. 1 Course of twin pregnancy rates in Hessen 20002015, twins $=$ number of twin pairs, total $=$ total deliveries, $n=13,725 / 805,536$ deliveries, $p<0.00001+$, statistical analyses according to logistic regression 
of inclusion and exclusion criteria data sets from 10,603 twin pregnancies $(77.3 \%)$ remained for further analyses.

The characteristics of the study group are shown in Table 1. More than 55\% of the women were primiparous, about $38 \%$ did not work when registering and roughly $10 \%$ did not have a partner. Among the twin pairs, 36\% had different sexes, and same sex twins showed an even distribution between males and females.

The mean maternal weight at the first examination increased from $68.2 \mathrm{~kg}$ in 2000 to $71.2 \mathrm{~kg}$ in 2015 $(p<0.001)$, whereas the mean maternal height did not change $(p=0.58)$. Consequently, the early mean maternal BMI increased from $24.4 \mathrm{~kg} / \mathrm{m}^{2}$ in 2000 to $25.4 \mathrm{~kg} / \mathrm{m}^{2}$ in $2015(p<0.0001)$.

Table 1 Characteristics of the study group $(n=10,603 / 13,725$ total twin deliveries between 2000 and 2015 in Hessen, Germany), 3122 pregnancies excluded after plausibility control

\begin{tabular}{lc}
\hline Characteristics & Mean $(\mathrm{SD})$ or $n(\%)$ \\
\hline Maternal age (years) & $32.1(5.09)$ \\
Maternal weight at 1st examination $(\mathrm{kg})$ & $69.6(15.2)$ \\
Maternal height $(\mathrm{cm})$ & $167(6.39)$ \\
Maternal BMI at 1st examination $\left(\mathrm{kg} / \mathrm{m}^{2}\right)$ & $24.8(5.10)$ \\
Week of 1st examination & $8.24(1.90)$ \\
Gestational age at birth (weeks) & $35.8(2.80)$ \\
Sex of twins & \\
Male/female & $3831(36.1 \%)$ \\
Female/female & $3382(31.9 \%)$ \\
Male/male & $3390(32.0 \%)$ \\
Mother without partner & \\
Yes & $871(9.93 \%)$ \\
No & $7896(90.1 \%)$ \\
Mother's origin & \\
German & $8621(81.3 \%)$ \\
Other nationalities & $1982(18.7 \%)$ \\
Previous deliveries & \\
0 & $5995(56.8 \%)$ \\
1 & $3213(30.4 \%)$ \\
2 & $922(8.74 \%)$ \\
3 or more & $422(4.00 \%)$ \\
Work & \\
Housewife (at start of pregnancy) & $2846(38.1 \%)$ \\
Still in education & $151(2.02 \%)$ \\
Worker & $225(3.01 \%)$ \\
Employee & $1538(20.6 \%)$ \\
\hline Academic position & \\
\hline
\end{tabular}

$S D$ standard deviation, $n$ absolute number

${ }^{\mathrm{a}}$ Missing values 1836

${ }^{\mathrm{b}}$ Missing values 51

${ }^{\mathrm{c}}$ Missing values 3132
As shown in Fig. 2a, the mean maternal age rose significantly between 2000 and 2015 from 31.4 to 32.9 years $(p<0.0001$, Fig. 2a) and showed an even larger increase among primiparous women: from 30.8 years in 2000 to 32.9 years in $2015(p<0.00001)$. The other maternal parameters are shown in Fig. 2c, d. The mean maternal GWG increased from 567 to $586 \mathrm{~g} /$ week ( $p=0.001$, Fig. 2b).

The cutoff for a "low gestational weight gain" defined as below the 25th quartile was $419 \mathrm{~g} /$ week and for "excessive gestational weight gain" defined as above the 75th quartile was $692 \mathrm{~g} /$ week. Although a growing absolute and relative number of women had a BMI of $30 \mathrm{~kg} / \mathrm{m}^{2}$ or higher $(p<0.001)$ at their first examination, there was no significant change in the rates of underweight women $(p=0.14)$ (Fig. 2c). The rates of HDP did also not change significantly between 2000 and 2015 ( $p=0.77$, Fig. 2d).

Figure $3 \mathrm{a}-\mathrm{d}$ shows the course of total, secondary and emergency caesareans and of PPH.

There was a significant increase of total and secondary caesarean deliveries from 68.6 and $20.6 \%$ in 2000 to $73.3 \%$ and 39.8\%, respectively, in 2015 ( $p<0.001$, Fig. 3a, b). No significant change was observed in the rates of emergency caesarean delivery ( $p=0.93$, Fig. $3 c)$ and in the rates of PPH $(p=0.12$, Fig. 3d).

Apart from these figures we analyzed the rates of caesareans only in the second twin, e.g. combined delivery.

In 2000 , this rate was $3 / 675(0.4 \%)$, but increased up to $20 / 726(2.9 \%)$ in 2010 in only 10 years $(p<0.01)$.

The examined neonatal outcomes are illustrated in Figs. 4 and 5, including the categories of preterm birth and BW. The rates of early preterm birth $(<28$ and $28+0$ to $33+6$ weeks) $(p<0.01$, Fig. $4 a)$ and newborns with a BW $<1500 \mathrm{~g}(p<0.001$, Fig. 4b) all increased. Rates of stillbirth ( $p=0.85$, Fig. $4 c)$, perinatal mortality $(p=0.82$, Fig. 4d), NICU admissions (0.28, Fig. 5a) or APGAR scores after 5 min below 7 ( $p=0.16$, Fig. $5 b$ ) did not significantly change between 2000 and 2015. Even worse, in spite of increasing caesarean rates, the rates of twins with a $\mathrm{pH}$ in the umbilical artery at birth below 7.1 did not decrease, but increased during the observation period ( $p=0.03$, Fig. 5 c).

\section{Discussion}

\section{Principal findings}

Between 2000 and 2015, twinning rates in this German cohort were rising from 1.5 to $1.9 \%$ (29\%) parallel to a rise of maternal age from 31.4 to 32.9 years (4.8\%) and of a BMI from 24.4 to $25.4 \mathrm{~kg} / \mathrm{m}^{2}$ (4.1\%). Similarly, there was a $3.3 \%$ increase of mean GWG from 567 to $586 \mathrm{~g} /$ week between 2000 and 2015. The increasing rates of caesareans were associated with an increase of early preterm birth, twins with 


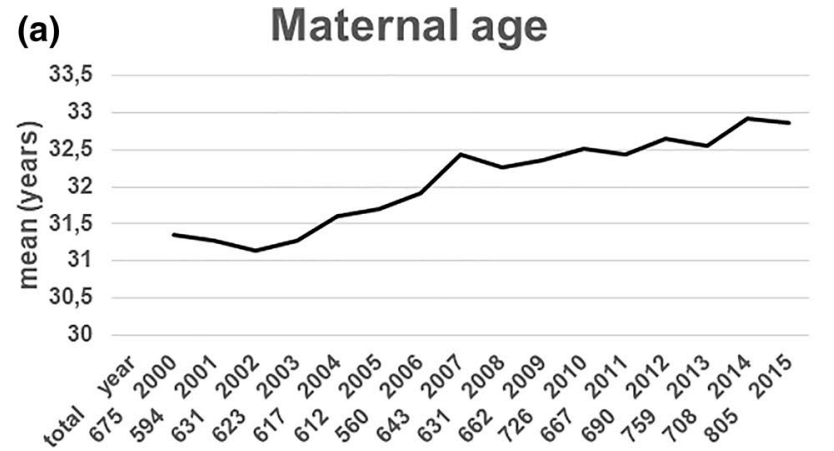

\section{(c) Maternal BMI categories}

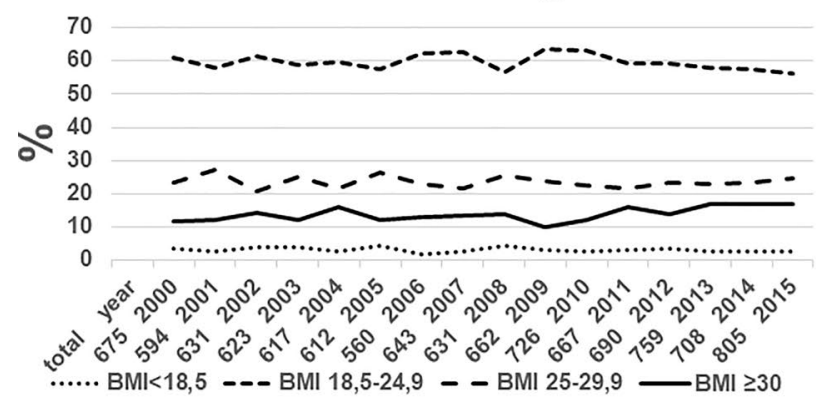

Fig. 2 Course of maternal outcomes between 2000 and 2015, $n=10,603$, total $=$ total twin deliveries, cases $=$ absolute incidence of specific outcome, $+=$ positive correlation, $-=$ negative correlation, statistical analysis by linear $(\mathbf{a}, \mathbf{b})$ or logistic $(\mathbf{c}, \mathbf{d})$ regression. a Mean maternal age (years): $p<0.0001+$, b mean maternal weight

a $\mathrm{BW}<1500 \mathrm{~g}$ and increased rates of acidosis $(\mathrm{pH}<7.1$ in the umbilical artery) and were not accompanied with a significant change in stillbirths, perinatal mortality or admission of the twins to a NICU.

\section{Meaning of the findings}

An increasing twinning rate is also observed in other countries and continents $[9,16-19]$ up to date. Maternal age, weight, genetic factors and artificial reproductive technologies (ART) are the main determinants of twinning and higher-order multiple rates [20]. To compensate overenthusiastic use of ART, several countries established regulations to reduce an uncontrolled origin of twin and higher-order multiple pregnancies caused by ART [21].

But even within Europe, legislation and practice vary considerably [22] resulting in rates of deliveries after ART between $0.54 \%$ in Malta and $4.1 \%$ in Denmark [23] which may impact the country-specific twinning rates. The policy of single versus double or multiple embryo transfer also plays an important role. It was shown that electively choosing single blastocyst transfer can significantly reduce the risk of multiples among women $<40$ years without compromising their pregnancy rates [24]. Between 2006 and 2017,
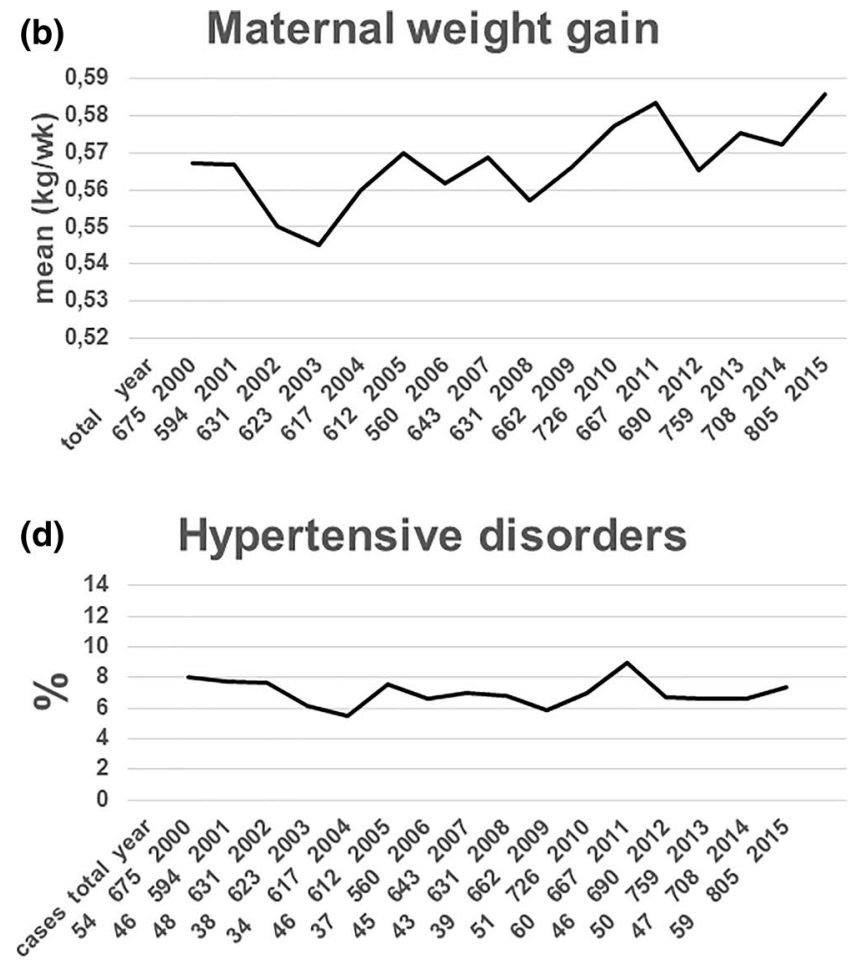

gain/gestational week (kg/week): $p=0.001+, \mathbf{c}$ maternal body mass index categories $(\%)$ at 1 st examination $(<14$ gestational weeks): underweight: $n=324, p=0.14$; normal weight: $n=6321, p=0.11$; overweight: $n=2489, p=0.62$; obese: $n=1469, p<0.001+$, $\mathbf{d}$ hypertensive disorders in pregnancy (\%): $n=743, p=0.77$

the total fertility rate in Europe ranged between 1.54 and 1.61 children/woman [25] although a mean of 2.1 children/ woman is considered to keep the population stable in developed countries [26]. Therefore, health-care politicians and health-care providers have to responsively balance and set their political priorities accordingly.

Similarly to the rising maternal age in this German cohort, the mean age of women at childbirth in 28 countries of the EU increased from 29.6 years in 2006 to 30.7 years in 2017 [27]. Older women are more likely to have twins, a high BMI and to be delivered by a caesarean $[28,29]$ which explains the inter-relationships of our results. Similar developments have been described:

With respect to the delivery mode the EURO-PERISTAT study already reported on large varieties in caesareans within Europe for different indications [30]. For multiple gestations, the rate of caesareans varied from north to south with $31.1 \%$ in Iceland to $98.6 \%$ in Malta. In central Europe, the rates were $43.9 \%$ in the Netherlands, $54.8 \%$ in France and $74.8 \%$ in Germany. Studies considering changing rates over time were published from Israel, whereby the authors reported on a total increase of caesarean rates in twins from $43.4 \%$ in 1995 to $66.0 \%$ in 2015 with increasing numbers only in non-laboring women [31]. In our cohort, primary caesareans 


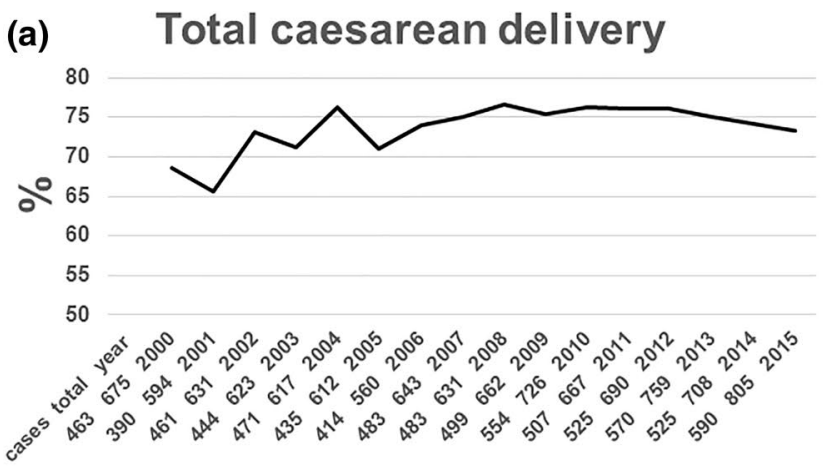

(c) Emergency Caesarean delivery

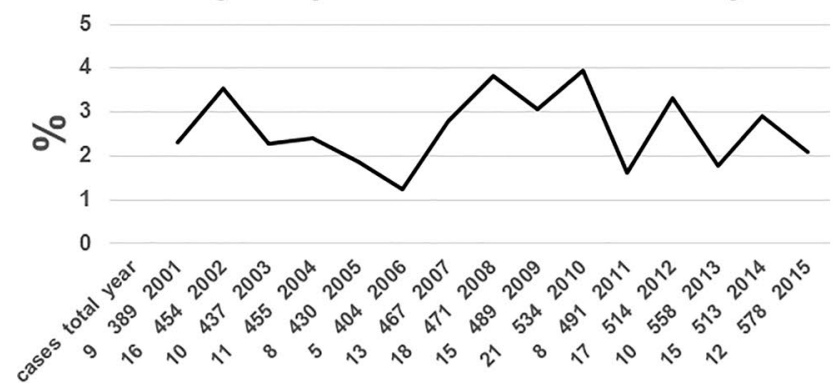

Fig. 3 Course of caesarean deliveries and postpartum haemorrhage between 2000 and 2015, $n=10,603$, total=total twin deliveries, cases $=$ absolute incidence of specific outcome, $+=$ positive correlation, $-=$ negative correlation all statistical analyses by logistic regression. a Total caesarean delivery $(\%): n=7814, p<0.001+$, b

did not increase. Similarly to our results, the increasing caesarean rates in Israel were not combined with lower rates of Apgar score $<7$ at $5 \mathrm{~min}$ or of PPH during this period [31].

In the US, caesarean rates in twins increased from $53.4 \%$ in 1995 to $75.0 \%$ in 2008. It was worrisome that these were not indicated by higher rates of obstetric or medical complications [32]. The total increase of caesareans in twin pregnancies in Western countries and the significant increase of secondary caesareans in this German cohort are most probably caused by a lack of skills in vaginal twin delivery and the fear of malpractice cases: Accordingly, we found an increase of caesareans in only the second twin within our cohort from $3 / 675(0.4 \%)$ to $20 / 726(2.8 \%)$. A survey in the US stated that despite national guidelines that encourage vaginal twin birth, concerns remain about the availability of skilled obstetricians [33]. Therefore, we have published detailed teaching programmes on this issue $[34,35]$. We also plan to perform a survey among residents based on the same evaluated questionnaire as by Easter et al. [33] and then to provide focused interventions of simulation-based training and provider support to increase obstetricians' comfort with vaginal twin vaginal delivery (work in progress, supported by the Clara Angela Foundation and the German AG Twin Pregnancy). (b) Secondary Caesarean delivery

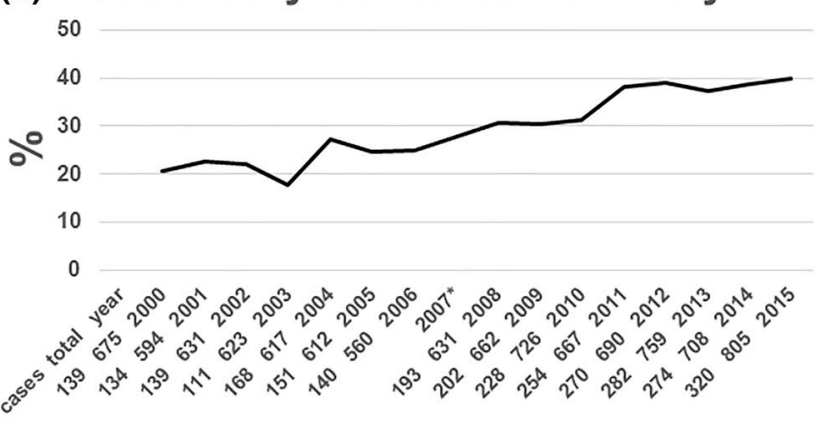

(d) Postpartum haemorrhage

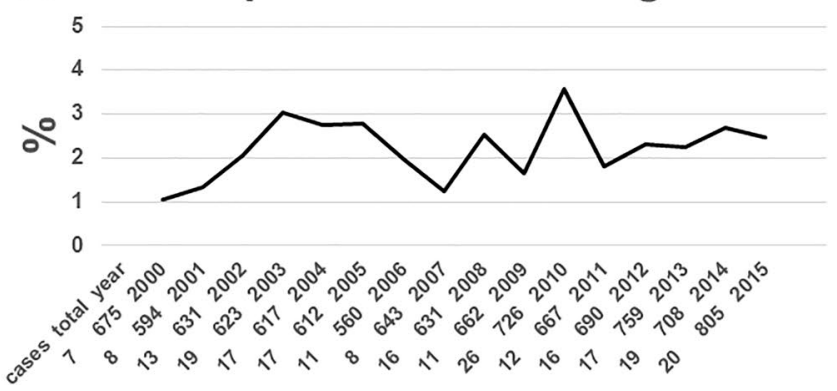

secondary caesarean delivery $(\%): n=3005, p<0.001+$, *data from 2007 was excluded due to missing values. c Emergency caesarean delivery (\%): $n=188, p=0.93$ (no data available in 2000). d Postpartum haemorrhage $>1000 \mathrm{ml}(\%): n=237, p=0.12$

Since excessive gestational weight gain (EGWG) has been identified as another risk factor for caesarean delivery rates [7, 36], the increase of EGWG may also explain the rising rates of caesareans in our cohort. Therefore, the here given quartiles could be of tremendous help for clinicians to avoid accelerated or decreasing weight gain in mothers of twins even within weekly controls. Although several studies have shown that EGWG and a high pre-pregnancy BMI lead to higher rates of HDP and preeclampsia [7, 8, 37, 38], this could not be demonstrated in our cohort which might have partly be caused by the indirect determination of HDP.

Studies on the effect of maternal weight on preterm births in singleton pregnancies are contradicting: in two studies overweight and obese women had increased risks of provider-initiated preterm delivery, but decreased risks of spontaneous preterm births [39, 40]. However, several studies consistently showed that in twin pregnancies a high maternal BMI increases the risk for all kinds of preterm deliveries [41, 42], and one study indicated that this was even the case for spontaneous preterm births [43]. The same association between maternal overweight or obesity and preterm births has been proven among twin pregnancies conceived by ART [44]. Thereby, a high maternal age does not seem to have a significant impact on the rates of 


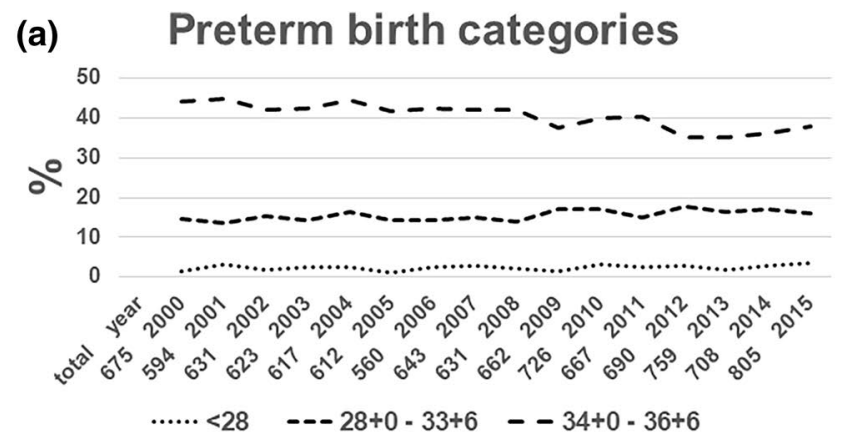

(c)

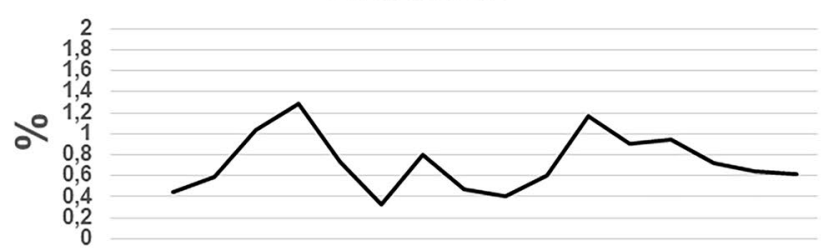

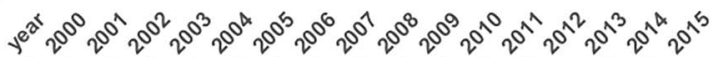

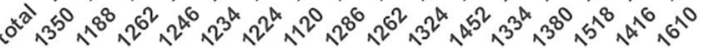

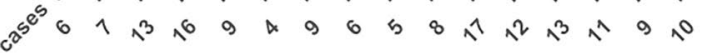

Fig. 4 Course of neonatal outcomes (I) between 2000 and 2015, $n=21,206$, total $=$ total twin deliveries (a) or newborn twins (b-d), cases $=$ absolute incidence of specific outcome, $+=$ positive correlation, $-=$ negative correlation, all statistical analyses by logistic regression. a Preterm deliveries (\%) in categories: delivery $<28$ weeks: $n=520, p<0.01+$; delivery between $28+0$ and

preterm birth in twin pregnancies [45] and was even discussed to decrease the risk [46]. Whether the increasing rates of preterm deliveries in our cohort can be explained by a high BMI should be analyzed by multivariate regression models.

With respect to the birthweight of twins our results suggest that the rate of twins with a $\mathrm{BW}<1500 \mathrm{~g}$ increased in parallel with increasing pre-pregnancy BMI and EGWG, which is in contrast to other results $[8,36,47]$. Pre-pregnancy maternal underweight and low maternal GWG are reported to be associated with higher rates of preterm birth, low BW or SGA and NICU admissions [37, 48-52]. In our cohort, the rate of underweight women did not change with time and thus can hardly explain the increasing rates of low BW and prematurity in twins. Therefore, it might still be suspected that iatrogenic early caesareans might have led to increasingly unfavourable outcomes.

Long-term maternal and neonatal outcomes are strongly influenced by high maternal BMI and EGWG in singleton pregnancies showing higher risks for postpartum weight retention and cardiovascular events for the mothers [2, 3, 53] as well as higher rates of childhood obesity and even lower life expectancy in the offspring $[4,54]$. However, the effects have not yet been demonstrated specifically for mothers of

\section{(b) Birth weight categories}

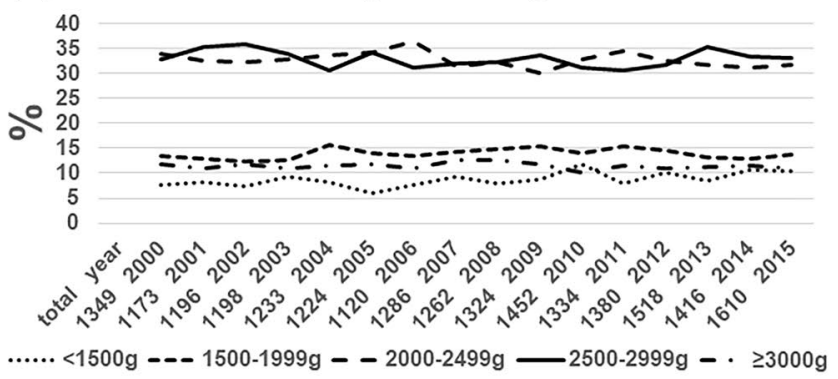

(d)

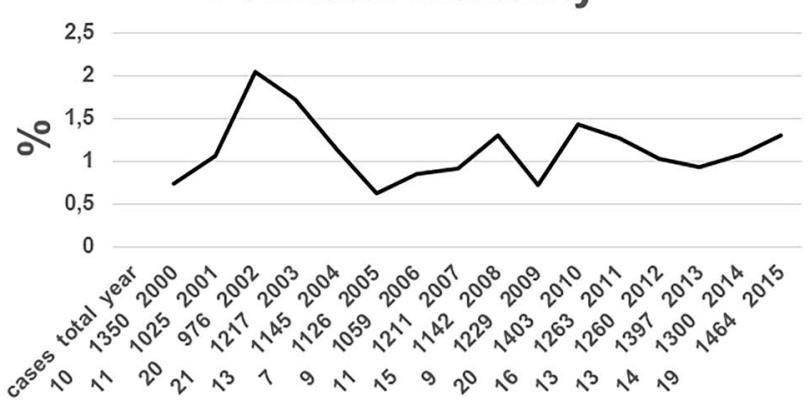

$33+6$ weeks: $n=3301, p=0.002+$; delivery between $34+0$ and $36+6$ weeks: $n=8548, p<0.001-$. b Birth weight (\%) in categories: $<1500$ g: $n=1860, p<0.001+; 1500-1999$ g: $n=2941, p=0.41$; 2000-2499 g: $n=6903, p=0.07 ; 2500-2999 \mathrm{~g}: n=6958, p=0.33$; $>3000 \mathrm{~g}: n=2413, p=0.50$. c Stillbirth (\%): $n=155, p=0.85$. d Perinatal mortality $(\%): n=221, p=0.82$

twins and their offspring and should therefore be analyzed in future trials.

\section{Clinical implications}

In general, women need to be informed about the risks of twin pregnancies and the consequences of a deviating BMI or GWG for both, mother and their offspring which differ from singleton pregnancies. Specific results cannot be concluded from only descriptive analyses, but require multivariate analyses (work in progress).

The IOM guidelines have proven to be an evidence-based framework to help in the surveillance of maternal weight gain for singletons [6]. Even though the recommendations for twin pregnancies were only provisional and related to the whole duration of pregnancy, some studies showed that women with an adequate as compared to women whose total weight gain was less than recommended had lower rates of SGA and preterm birth, whereas no significant improvement was shown when data were compared with women of EGWG [50, 55, 56]. Therefore, the pragmatic cutoffs we here provide for weekly weight gain in the form of quartiles may already enable obstetricians to identify unusually high or low GWG and to provide better counseling for women 
(a)

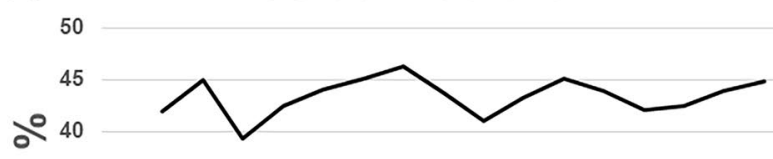

35

30

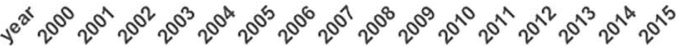

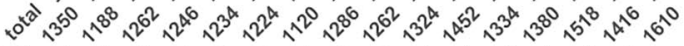

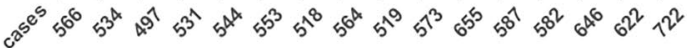

(c)

PH umbilical artery $<7,1$

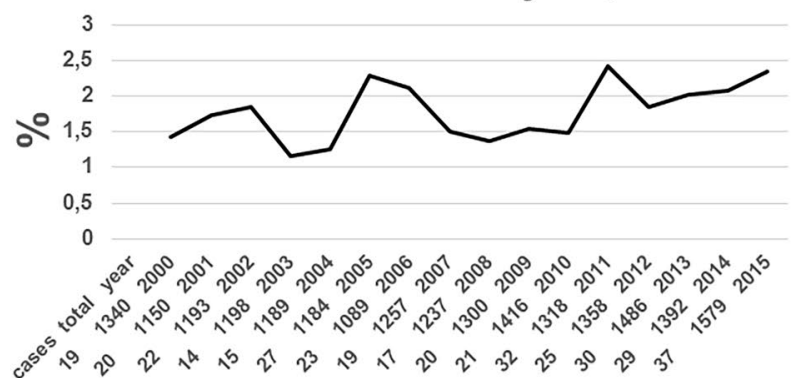

Fig. 5 Course of neonatal outcomes (II) between 2000 and 2015, $n=21$ 206, total = total newborn twins, cases $=$ absolute incidence of specific outcome, $+=$ positive correlation, $-=$ negative correlation, all statistical analyses by logistic regression. a NICU admissions (\%): $n=9213, p=0.28$. b Newborns with an APGAR below 7 after 5 min

pregnant with twins. Presently, we perform multivariate analysis models to further evaluate the impact of both insufficient and excessive GWG on maternal and neonatal outcomes in twin pregnancies.

\section{Strengths and weaknesses}

The strength of the study is that the cohort of twin pregnancies is large enough to demonstrate significant changes during a time period of 15 years which allows to compare regional and national trends in comparison to other German or European cohorts. In addition, the size of the total cohort was large enough to calculate quartiles of weight gain during twin pregnancy which were not yet provided to clinicians before.

Our study also has weaknesses: data from perinatal registers in Germany are not sufficiently controlled in terms of completeness of data and plausibility. Therefore, it took us 1 year to correctly select only plausible data. Nevertheless, data on GDM appeared retrospectively unreliable in terms of method and gestational age of diagnosis. This is why we did not further analyze GDM in our cohort. However, there are recent data that in contrast to singleton pregnancies, GDM in twin pregnancies is not associated with HDP or pour (b) APGAR 5 $<7$

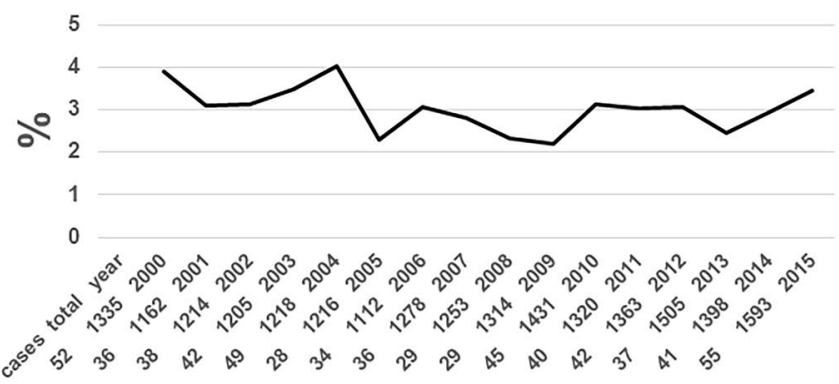

(d) APGAR 5'<7 \& pH umbilical artery $<7,1$

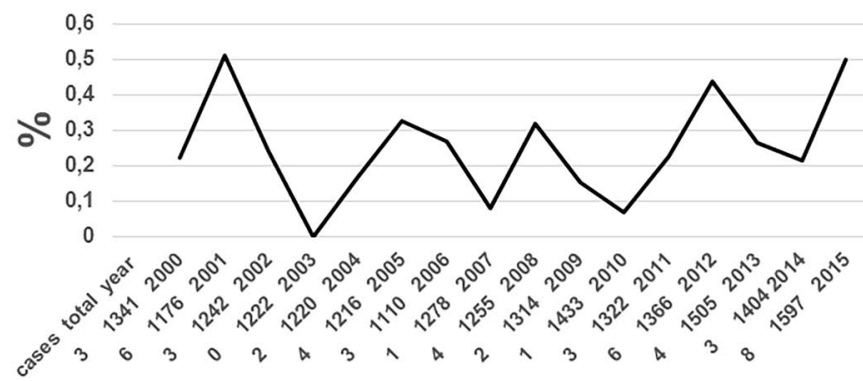

(\%): $n=633, p=0.16$. $\mathrm{c}$ Newborns with a $\mathrm{pH}$ in the umbilical artery below 7.1 (\%): $n=370, p=0.03+$. d Newborns with an APGAR $5^{\prime}$ below 7 and a $\mathrm{pH}$ in the umbilical artery below $7.1(\%): n=53$, $p=0.39$

neonatal outcome but with accelerated fetal growth, which later might change the metabolic morbidity [57].

Another weakness is that the registry did not allow differentiating between mono- and dichorionic twins or between the origin of pregnancy. Thus we were not able to determine the individual impact of ART on the increase of twinning rates and the outcome of chorionicity and ART pregnancies as compared to spontaneous origin.

Not analyzing a causal relationship between maternal weight characteristics in pregnant mothers of twins and the outcome could be regarded as a weakness but this was intentiously postponed to work in progress.

\section{Conclusion}

The global and national trends of the obesity epidemic were equally observed in this German cohort of twin pregnancies. In parallel, there was no improvement but even an aggravation of maternal and neonatal outcomes reflected by increasing rates of caesareans and of preterm birth, low BW and low pH values at birth between 2000 and 2015 . This should increase awareness among policy makers and stimulate health-care providers to intensify counselling of pregnant mothers of twins. The here defined cutoff values 
for maternal weight gain in twin pregnancies are a chance to identify abnormal maternal weight gain. In addition, iatrogenic preterm caesareans and combined deliveries should be avoided and skills in vaginal delivery of twins improved.

Acknowledgements Open Access funding provided by Projekt DEAL. The authors would like to thank Dr. med Björn Misselwitz and the "Geschäftsstelle Qualitätssicherung Hessen" for their support in the acquisition of data.

Author contribution JS: data management, data analysis, manuscript writing; NT: data management, data analysis; KN: data management; BA: project development, data analysis, manuscript writing.

\section{Compliance with ethical standards}

Conflict of interest The authors declare that they have no competing interests.

Ethical approval This study is an analysis of exclusively anonymized secondary data. In accordance with the guidelines of the working group of secondary data analyses (AGENS) as part of DGSMP and DGEpi [58], it was not submitted to an ethical committee.

Informed consent Informed consent was not necessary because the data were anonymous.

Open Access This article is licensed under a Creative Commons Attribution 4.0 International License, which permits use, sharing, adaptation, distribution and reproduction in any medium or format, as long as you give appropriate credit to the original author(s) and the source, provide a link to the Creative Commons licence, and indicate if changes were made. The images or other third party material in this article are included in the article's Creative Commons licence, unless indicated otherwise in a credit line to the material. If material is not included in the article's Creative Commons licence and your intended use is not permitted by statutory regulation or exceeds the permitted use, you will need to obtain permission directly from the copyright holder. To view a copy of this licence, visit http://creativecommons.org/licenses/by/4.0/.

\section{References}

1. Sepúlveda J, Murray C (2014) The state of global health in 2014. Science 345(6202):1275-1278. https://doi.org/10.1126/scien ce. 1257099

2. Poston L, Caleyachetty R, Cnattingius S et al (2016) Preconceptional and maternal obesity: epidemiology and health consequences. Lancet Diabetes Endocrinol 4(12):1025-1036. https:// doi.org/10.1016/S2213-8587(16)30217-0

3. Arabin B, Stupin JH (2014) Overweight and obesity before, during and after pregnancy: part 2: evidence-based risk factors and interventions. Geburtshilfe Frauenheilkd 74(7):646-655. https:// doi.org/10.1055/s-0034-1368462

4. Reynolds RM, Allan KM, Raja EA et al (2013) Maternal obesity during pregnancy and premature mortality from cardiovascular event in adult offspring: follow-up of 1,323,275 person years. BMJ 347:f4539. https://doi.org/10.1136/bmj.f4539
5. Bodnar LM, Pugh SJ, Abrams B et al (2014) Gestational weight gain in twin pregnancies and maternal and child health: a systematic review. J Perinatol 34(4):252-263. https://doi.org/10.1038/ jp.2013.177

6. Rasmussen KM, Yaktine AL (2009) Weight gain during pregnancy: re-examining the guidelines. National Academies Press,Washington (DC). https://doi.org/10.17226/12584

7. Gavard JA, Artal R (2014) Gestational weight gain and maternal and neonatal outcomes in term twin pregnancies in obese women. Twin Res Hum Genet 17(2):127-133. https://doi.org/10.1017/ thg.2013.91

8. Pettit KE, Lacoursiere DY, Schrimmer DB et al (2016) Maternal and neonatal outcomes in women with twin pregnancies with excessive gestational weight gain. J Matern Fetal Neonatal Med 29(13):2182-2185. https://doi.org/10.3109/14767058.2015.10796 13

9. Kurosawa K, Masuno M, Kuroki Y (2012) Trends in occurrence of twin births in Japan. Am J Med Genet A 158A(1):75-77. https://doi.org/10.1002/ajmg.a.34362

10. Glinianaia SV, Rankin J, Sturgiss SN et al (2013) The north of England survey of twin and multiple pregnancy. Twin Res Hum Genet 16(1):112-116. https://doi.org/10.1017/thg.2012.65

11. Martin JA, Hamilton BE, Sutton PD et al (2006) Births: final data for 2004. Natl Vital Stat Rep 55(1):1-101

12. Martin JA, Hamilton BE, Osterman MJK et al (2018) Births: final data for 2016. Natl Vital Stat Rep 67(1):1-55

13. Tabellen Bevölkerung (15.06.2019). Internet: https://statistik. hessen.de/zahlen-fakten/bevoelkerung-gebiet-haushalte-famil ien/bevoelkerung/tabellen. Accessed 15 Jun 2019

14. World Health Organization. WHOIWhat is overweight and obesity? Internet: https://www.who.int/dietphysicalactivity/child hood_what/en/. Accessed 30 Jun 2019

15. Brown MA, Magee LA, Kenny LC et al (2018) Hypertensive disorders of pregnancy: ISSHP classification, diagnosis, and management recommendations for international practice. Hypertension 72(1):24-43. https://doi.org/10.1161/HYPER TENSIONAHA.117.10803

16. Martin JA, Hamilton BE, Osterman MJK et al (2018) Births: final data for 2017. Natl Vital Stat Rep 67(8):1-50

17. Vayssière C, Benoist G, Blondel B et al (2011) Twin pregnancies: guidelines for clinical practice from the French College of Gynaecologists and Obstetricians (CNGOF). Eur J Obstet Gynecol Reprod Biol 156(1):12-17. https://doi.org/10.1016/j. ejogrb.2010.12.045

18. Tandberg A, Bjørge T, B ørdahl PE et al (2007) Increasing twinning rates in Norway, 1967-2004: the influence of maternal age and assisted reproductive technology (ART). Acta Obstet Gynecol Scand 86(7):833-839. https://doi.org/10.1080/00016 340701417323

19. Boyle B, McConkey R, Garne E et al (2013) Trends in the prevalence, risk and pregnancy outcome of multiple births with congenital anomaly: a registry-based study in 14 European countries 1984-2007. BJOG 120(6):707-716. https://doi. org/10.1111/1471-0528.12146

20. Blondel B, Kaminski M (2002) Trends in the occurrence, determinants, and consequences of multiple births. Semin Perinatol 26(4):239-249

21. Allan S, Balaban B, Banker M, Brinsden P, Buster J, Mocanu E, Pai H, Le Roux P (2016) IFFS surveillance 2016. Wolters Kluwer Health, Philadelphia, PA. https://doi.org/10.1097/ GRH.0000000000000001

22. Präg P, Mills MC. Assisted reproductive technology in Europe: usage and regulation in the context of cross-border reproductive care. In: Kreyenfeld M, Konietzka D, editors. Childlessness in Europe: contexts, causes, and consequences. Demographic research monographs, a series of the Max Planck Institute for 
Demographic Research. Cham: Springer International Publishing; 2017. p. 289-309. https://doi.org/10.1007/978-3-319-44667 $-7 \_14$

23. da Silva MO, Jahn A, Olsen J, Karro H, Temmerman M, Gissler M, Fronteira I (2011) The reproductive health report: the state of sexual and reproductive health within the European Union. Eur J Contracept Reprod Health Care 16(Suppl 1):S1-S70. https://doi. org/10.3109/13625187.2011.607690

24. Mullin CM, Fino ME, Talebian S et al (2010) Comparison of pregnancy outcomes in elective single blastocyst transfer versus double blastocyst transfer stratified by age. Fertil Steril 93(6):18371843. https://doi.org/10.1016/j.fertnstert.2008.12.137

25. European Commission. Eurostat - tables, graphs and maps interface (TGM) table total fertility rate. https://ec.europa.eu/eurostat/ $\operatorname{tgm} /$ refreshTableAction.do?tab=table \&plugin $=1 \&$ pcode $=\operatorname{tps} 00$ 199\&language $=$ en. Accessed 22 Sept 2019

26. Craig J (1994) Replacement level fertility and future population growth. Popul Trends 78:20-22

27. European Commission. Eurostat-tables, graphs and maps interface (TGM) table mean age of women at childbirth. https://ec.europ a.eu/eurostat $/$ tgm/table.do?tab=table \&init $=1 \&$ language $=$ en $\&$ pcode $=$ tps00017\&plugin $=1$. Accessed 22 Sept 2019

28. Gluck O, Mizrachi Y, Bar J et al (2018) The impact of advanced maternal age on the outcome of twin pregnancies. Arch Gynecol Obstet 297(4):891-895. https://doi.org/10.1007/s00404-018-4656-1

29. Fox NS, Rebarber A, Dunham SM et al (2009) Outcomes of multiple gestations with advanced maternal age. J Matern Fetal Neonatal Med 22(7):593-596. https://doi.org/10.1080/14767050902801819

30. Macfarlane AJ, Blondel B, Mohangoo AD et al (2016) Wide differences in mode of delivery within Europe: risk-stratified analyses of aggregated routine data from the Euro-Peristat study. BJOG 123(4):559-568. https://doi.org/10.1111/1471-0528.13284

31. Tal A, Zafran N, Peretz H et al (2019) Trend in cesarean delivery rate among twin pregnancies over a 20 years epoch and the accompanied maternal and perinatal outcomes. Eur J Obstet Gynecol Reprod Biol X 3:100023. https://doi.org/10.1016/j.eurox.2019.100023

32. Lee HC, Gould JB, Boscardin WJ et al (2011) Trends in cesarean delivery for twin births in the United States: 1995-2008. Obstet Gynecol 118(5):1095-1101. https://doi.org/10.1097/AOG.0b013 e3182318651

33. Easter SR, Taouk L, Schulkin J et al (2017) Twin vaginal delivery: innovate or abdicate. Am J Obstet Gynecol 216(5):484-488.e4. https ://doi.org/10.1016/j.ajog.2017.01.041

34. Arabin B, Kyvernitakis I, Hamza A et al (2019) Vaginal delivery of the second twin in unengaged cephalic presentation. J Matern Fetal Neonatal Med. https://doi.org/10.1080/14767058.2019.1590333

35. Arabin B, Kyvernitakis I (2011) Vaginal delivery of the second nonvertex twin: avoiding a poor outcome when the presenting part is not engaged. Obstet Gynecol 118(4):950-954. https://doi.org/10.1097/ AOG.0b013e31822f0f8a

36. Yeh J, Shelton JA (2007) Association of pre-pregnancy maternal body mass and maternal weight gain to newborn outcomes in twin pregnancies. Acta Obstet Gynecol Scand 86(9):1051-1057. https:// doi.org/10.1080/00016340701417026

37. Pécheux O, Garabedian C, Drumez E et al (2019) Maternal and neonatal outcomes according to gestational weight gain in twin pregnancies: are the institute of medicine guidelines associated with better outcomes? Eur J Obstet Gynecol Reprod Biol 234:190-194. https ://doi.org/10.1016/j.ejogrb.2019.01.010

38. Balki I, Sheth H, Shafey A et al (2019) Maternal BMI in twin pregnancies and impact on neonatal outcomes in the level I unit: a retrospective cohort study. J Obstet Gynaecol Can. https://doi. org/10.1016/j.jogc.2018.11.011

39. Parker MG, Ouyang F, Pearson C et al (2014) Prepregnancy body mass index and risk of preterm birth: association heterogeneity by preterm subgroups. BMC Pregnancy Childbirth 14:153. https://doi. org/10.1186/1471-2393-14-153

40. Silva F, Souza RT, Cecatti JG et al (2019) Role of body mass index and gestational weight gain on preterm birth and adverse perinatal outcomes. Sci Rep 9(1):13093. https://doi.org/10.1038/s41598-01949704-x

41. Suzuki S, Inde Y, Miyake H (2010) Maternal obesity as a risk factor for very pre-term delivery in dichorionic twin pregnancies. J Obstet Gynaecol 30(4):354-356. https://doi.org/10.3109/0144361100 3650241

42. Obaidly S, Parrish J, Murphy KE et al (2014) Maternal pre-gravid body mass index and obstetric outcomes in twin gestations. J Perinatol 34(6):425-428. https://doi.org/10.1038/jp.2014.29

43. Sung SJ, Lee SM, Kim S et al (2018) The risk of spontaneous preterm birth according to maternal pre-pregnancy body mass index in twin gestations. J Korean Med Sci 33(13):e103. https://doi. org/10.3346/jkms.2018.33.e103

44. Dickey RP, Xiong X, Gee RE et al (2012) Effect of maternal height and weight on risk of preterm birth in singleton and twin births resulting from in vitro fertilization: a retrospective cohort study using the Society for Assisted Reproductive Technology Clinic Outcome Reporting System. Fertil Steril 97(2):349-354. https:// doi.org/10.1016/j.fertnstert.2011.11.017

45. Lee Y-J, Kim M-N, Kim Y-M et al (2019) Perinatal outcome of twin pregnancies according to maternal age. Obstet Gynecol Sci 62(2):93-102. https://doi.org/10.5468/ogs.2019.62.2.93

46. Zipori Y, Linder R, Khatib N et al (2019) Advanced maternal age and perinatal outcome in twin pregnancies: a meta-analysis. J Matern Fetal Neonatal Med. https://doi.org/10.1080/14767 058.2019.1570112

47. Lima RJCP, Batista RFL, Ribeiro MRC et al (2018) Prepregnancy body mass index, gestational weight gain, and birth weight in the BRISA cohort. Rev Saude Publica 52:46. https://doi.org/10.11606/ s1518-8787.2018052000125

48. Fox NS, Stern EM, Saltzman DH et al (2014) The association between maternal weight gain and spontaneous preterm birth in twin pregnancies. J Matern Fetal Neonatal Med 27(16):1652-1655. https ://doi.org/10.3109/14767058.2014.898058

49. Chen Y, Liu Y, Zhang Y et al (2018) Gestational weight gain per pre-pregnancy body mass index and birth weight in twin pregnancies: a cohort study in Wuhan, China. Sci Rep 8(1):12496. https:// doi.org/10.1038/s41598-018-29774-z

50. Lutsiv O, Hulman A, Woolcott C et al (2017) Examining the provisional guidelines for weight gain in twin pregnancies: a retrospective cohort study. BMC Pregnancy Childbirth 17(1):330. https://doi. org/10.1186/s12884-017-1530-2

51. Greenan CW, Newman RB, Wojciechowski B et al (2017) Achievement of body mass index specific weight gain recommendations: impact on preterm birth in twin pregnancies. Am J Perinatol 34(13):1293-1301. https://doi.org/10.1055/s-0037-1603318

52. Ram M, Berger $\mathrm{H}$, Lipworth $\mathrm{H}$ et al (2019) The relationship between maternal body mass index and pregnancy outcomes in twin compared with singleton pregnancies. Int J Obes (Lond). https://doi. org/10.1038/s41366-019-0362-8

53. Nehring I, Schmoll S, Beyerlein A et al (2011) Gestational weight gain and long-term postpartum weight retention: a meta-analysis. Am J Clin Nutr 94(5):1225-1231. https://doi.org/10.3945/ ajcn.111.015289

54. Houghton LC, Ester WA, Lumey LH et al (2016) Maternal weight gain in excess of pregnancy guidelines is related to daughters being overweight 40 years later. Am J Obstet Gynecol 215(2):246.e1-246. e8. https://doi.org/10.1016/j.ajog.2016.02.034

55. Shamshirsaz AA, Haeri S, Ravangard SF et al (2014) Perinatal outcomes based on the institute of medicine guidelines for weight gain in twin pregnancies. J Matern Fetal Neonatal Med 27(6):552-556. https://doi.org/10.3109/14767058.2013.836177 
56. González-Quintero VH, Kathiresan ASQ, Tudela FJ et al (2012) The association of gestational weight gain per institute of medicine guidelines and pre-pregnancy body mass index on outcomes of twin pregnancies. Am J Perinatol 29(6):435-440. https://doi. org/10.1055/s-0032-1304824

57. Hiersch L, Berger H, Okby R et al (2019) Gestational diabetes mellitus is associated with adverse outcomes in twin pregnancies. Am J Obstet Gynecol 220(1):102.e1-102.e8. https://doi.org/10.1016/j. ajog.2018.10.027
58. Swart E, Gothe H, Geyer S et al (2015) Gute Praxis Sekundärdatenanalyse (GPS): Leitlinien und Empfehlungen. Gesundheitswesen 77(2):120-126. https://doi.org/10.1055/s-0034-1396815

Publisher's Note Springer Nature remains neutral with regard to jurisdictional claims in published maps and institutional affiliations. 